\title{
INVESTIGATION OF FLOW CHARACTERISTICS AND VORTEX FORMATIONS OF LAMBDA WING AT HIGH ANGLES OF ATTACK
}

\author{
M. Murat Yavuz ${ }^{*}$
}

\begin{abstract}
It is well known in literature that further stages of flow separation and vortex breakdown around wings can be able to cause stall of wings. These formations must be investigated carefully for new plane types. However, some limited studies are available, especially on lambda wing for high angles of attack. In this study, effect of angle of attack on flow characteristics and vortex breakdown around a lambda wing is investigated with a constant Reynolds number of 10000. Computational fluid dynamic analysis is used and results of high angles of attack of the wing are given up to $45^{0}$ which are not available in literature. Open water channel simulation is used. Vortex breakdown initially begins at an angle of $17^{0}$ and it almost reaches to tip of wing when angle of attack is equal to $25^{\circ}$. Vortices get stronger at further increments of angle of attack and they become to nearly equal length of wing at $45^{\circ}$. Rounding effect of leading edges is investigated for decreasing vortex magnitudes. Streamline, particle injection, iso-value of vortices and location of stagnation points are given, and they are discussed in detail.
\end{abstract}

\section{Keywords: Vortex Breakdown, Angle of Attack, Lambda Wing}

\section{INTRODUCTION}

The usage of unmanned combat air vehicles (UCAVs) creates a new field of study on the investigation of flow characteristics around specific wing geometries. Remote control properties provide some advantages on geometrical simplifications of UCAVs because aviator cabin requirement is not necessary at these planes. Wing geometry of UCAVs seems to be mostly delta, lambda and diamond shapes. Several studies are available on their flight performance, vortex formations and their control. Different flow regimes have been summarized around lee side of delta wings [1] in literature. These regimes can be observed as nine different flow structures. Lu and Zhu [2] detect three different more vortex formations; frog jump, double spiral and filiform spiral forms rather than spiral and bubble types around a delta wing. These vortices [3] cause instabilities in a review study about trailing vortices. They are mainly grouped in three stages by considering their formations; initial flow distribution, vortex formation and vortex breakdown. Vortex breakdown occurs after the flow separation on the wing by increasing angle of attack [6] has a dominant effect [4-5] on flight conditions and must be examined. Increasing the angle of attack [7] is one of the dominant sources that cause to formation of vortex breakdown and affects $[3,8]$ the whole flow regime around the wing. Vortex breakdown structure includes strong reversed flow [9-10] that occurs on sudden expansion of leading-edge vortices at a critical angle of attack [11-12] in unsteady flows. In that case, turbulent intensity [13] increases rapidly and leading-edge vortex kinetic energy is [10] transferred into kinetic energy of small vortices and turbulent kinetic energy. This energy transformation decreases aerodynamic performance and flow stability [14]. High dense reversed flow formation [15] occurs at the vortex breakdown locations, which decrease suction pressure and cause to decrease lift performance. The location of vortex breakdown moves [16] towards the tip of wing by increasing angle of attack and causes to stall, if vortex breakdown reaches to tip of the wing [6,17]. When angle of attack reaches critical values, moment effect [18] on lifting gets vanished from wing surfaces at the separation location of vortices.

Most of the UCAVs have delta wing geometry, which is one of the simplest unmanned combat air vehicles and several studies are available [10,19-23]. Formation of vortex breakdown around a delta wing is [24] searched with including sub-grid scale (SGS) method, which increases the accuracy of large Eddy simulations. Different

This paper was recommended for publication in revised form by Regional Editor Baha Zafer

${ }^{1}$ Department of Mechanical Engineering, Izmir Demokrasi University, Izmir, Turkey

${ }^{*} E$-mail address: murat.yavuz@idu.edu.tr

Orcid id:0000-0002-5892-0075

Manuscript Received 18 September 2018, Accepted 12 January 2019 
turbulent models (RANS, DES, and DDES) are [25] used on the numerical simulations of flow around a rounded leading-edge delta wing. Size and strength of vortex structures and effect of shear layers are observed. Flow around a double-delta wing is [26] investigated with an angle of attack from $10^{\circ}$ to $35^{\circ}$ by using SA-DES turbulence model. Leading edge separation and more inner vortex structures [27] are investigated for a delta wing with a rounded leading edge.

Several vortex structures are classified around the delta wings, especially with the usage of particle image velocimetry (PIV) in experimental studies. LEX (leading edge extension) vortices are one of the vortex types, include effective pressure field and support lift of the wing [28]. But they can cause fatigue failures and disturb overall flow regime around the wing. A relation is detected between LEX vortices and wing vortices in a study about delta wing [29]. Each of vortices can influence the other in the same manner, but also, they behave separately. Their breakdown time and locations can be different. In general, wing vortices are stronger than strake vortices; hence their breakdown occurs first [30].

Aeroelastic response of wings is also affected from flow characteristics around the wings. The increment of angle of attack of a delta wing [31] causes to increase aeroelastic resonant frequencies. Pashilkar [32] investigates a surface pressure model for observing aeroelastic responses of delta wing for high angles of attack conditions. Gordnier and Visbal [17] examine aeroelastic spectral analysis of wing deflection for a delta wing that the first structural mode has dominant effect between an angle of attack range of 50 and 400 . Aeroelastic response of a high aspect ratio wing is [33] investigated. The study emphasizes that effect of geometric nonlinearity is important for large deformation analysis.

The effect of vortex breakdown is tried to be eliminated or decreased by different researchers. Some applications achieve to control vortex breakdown like; addition of momentum to vortex core and periodic suction and blowing, which are summarized in a literature review study [34]. They are [35] used in limited areas and more investigations are needed. Application of frequency on wings, addition of flexibility to wings and plasma actuators [36] are also used on delta wings for trying to reduce vortex breakdown effects. It is pointed in literature review that the most effective application for delaying vortex breakdown is along-the-core blowing, which improves external pressure gradient. Gursul and Yang [37] investigate effect of pressure gradients on formation of vortex breakdown location and wing motion. External pressure gradient is detected as effective for chancing time lag of vortex breakdown location. When pitching motion is [38] applied on wing, an induced phase shift occurs between the wing motion and the onset of vortex breakdown, which depends on a continuous loop between of vortex breakdown position and angle of attack. The usage of delta wing actuators can be [39] able to delay the breakdown of the streamwise vortices with oscillation amplitudes of only one viscous scale. Passive and active vortex breakdown controls are [40] available and the usage of passive perturbations [41] achieves to delay vortex breakdown over delta wings. When active control is [40] used, vortex ring formations occur. Another application of perturbations on wings [42] prevents large-scale separation zone along the wing at high angle of attack. Flow characteristics of delta, diamond and lambda wings with stationary and perturbation conditions are investigated. The study illustrates that small amplitude perturbation at multiples of natural frequencies of vortices causes to delay the breakdown in a limited range [43]. Perturbations reduce the number of critical points of flow topology with decreasing magnitude of surface normal vorticity [45]. Also, application of small amplitude angular perturbations eliminates large scale separation zone along the wing at high angle of attack [46]. But the breakdown is not fully prevented, and high angle of attack causes to flow separations [47] in that application. Jet flaps are [48] investigated by using CFD analysis for prevention of the moment effect in another delaying applications.

The studies are mainly focused on the effect of attack, but in a limited range. In this study, new type of lambda wing geometry is investigated for observation of flow characteristics and vortex breakdown, especially for high angles of attack. Computational fluid dynamics (CFD), which is one of the numerical analyzing techniques, is used in the analysis. The relation between vortex formations and change of flow characteristics are clarified. Investigated wing has simple geometrical properties, but it also gains popularity in literature. Findings in this study will provide basic knowledge for prevention and delaying of vortex breakdown in further studies. 


\section{MATHEMATICAL MODELLING}

Investigations of flow characteristics around the wing are carried on by numerical analysis. The developed computer technology and solution methods increase the usage of numerical methods, which can illustrate flow disruptions and streamline topology better than experimental techniques. In literature, reattachment of shear layer [9] and vortex breakdown are observed better in CFD rather than experimental techniques, such as PIV and LDA (laser Doppler anemometry). No requirement of experimental setup and apparatus is also another advantage of this analysis.

\section{NAVIER-STOKES EQUATIONS (MASS AND MOMENTUM) FOR INCOMPRESSIBLE FLOW}

Basic flow characteristic equations are given in Equation 1-4. The first equation is the continuity equation and valid in whole solutions. Density and velocity vectors are included. Equations 2, 3 and 4 are called as NavierStokes equations. These equations provide relation between density, velocity and pressure in the flow changes.

$$
\begin{gathered}
\frac{\partial \rho}{\partial t}+\frac{\partial(\rho u)}{\partial x}+\frac{\partial(\rho v)}{\partial y}+\frac{\partial(\rho w)}{\partial z}=0 \\
\frac{\partial(\rho u)}{\partial t}+\frac{\partial\left(\rho u^{2}\right)}{\partial x}+\frac{\partial(\rho u v)}{\partial y}+\frac{\partial(\rho u w)}{\partial z}=-\frac{\partial P}{\partial x}+\frac{1}{R e}\left[\frac{\partial \tau_{x x}}{\partial x}+\frac{\partial \tau_{x y}}{\partial y}+\frac{\partial \tau_{x z}}{\partial z}\right] \\
\frac{\partial(\rho v)}{\partial t}+\frac{\partial(\rho u v)}{\partial x}+\frac{\partial\left(\rho v^{2}\right)}{\partial y}+\frac{\partial(\rho v w)}{\partial z}=-\frac{\partial P}{\partial y}+\frac{1}{R e}\left[\frac{\partial \tau_{x y}}{\partial x}+\frac{\partial \tau_{y y}}{\partial y}+\frac{\partial \tau_{y z}}{\partial z}\right] \\
\frac{\partial(\rho w)}{\partial t}+\frac{\partial(\rho u w)}{\partial x}+\frac{\partial(\rho v w)}{\partial y}+\frac{\partial\left(\rho w^{2}\right)}{\partial z}=-\frac{\partial P}{\partial z}+\frac{1}{R e}\left[\frac{\partial \tau_{x z}}{\partial x}+\frac{\partial \tau_{y z}}{\partial y}+\frac{\partial \tau_{z z}}{\partial z}\right]
\end{gathered}
$$

\section{NAVIER-STOKES EQUATIONS (MASS AND MOMENTUM) FOR INCOMPRESSIBLE FLOW}

The solution of analyzed system is represented with differential equations, which obey equilibrium, momentum and energy laws. The solution carries on these differential equations with application of essential and natural boundary conditions. A Reynolds number of 10000 is used in the analyses and turbulent flow regime is considered. In numerical analyses, different turbulence models are available in literature and more models are being still developed. One of the best-known turbulence models, k-epsilon (k-E) two equations model is used in the analyses, because of its accuracy in low Reynolds number turbulent flows. k-epsilon two equations turbulence model includes one algebraic equation and two partial differential equations [51]. Partial differential equations are turbulent kinetic energy, $\mathrm{k}$ (determines the energy in the turbulence) and turbulent dissipation rate, $\varepsilon$ (determines the scale of turbulence).

Turbulent kinetic energy and dissipation rate can be written [50] in analytical form as;

$$
\begin{gathered}
k=\frac{1}{2}\left[\overline{u^{\prime 2}}+\overline{v^{\prime 2}}+\overline{w^{\prime 2}}\right] \\
\varepsilon=v_{t} \overline{\left(\frac{\partial u_{i}^{\prime}}{\partial x_{j}}\right) *\left(\frac{\partial u_{i}^{\prime}}{\partial x_{j}}\right)}
\end{gathered}
$$

where $\mathrm{v}_{\mathrm{t}}$ is eddy viscosity, $\mathrm{u}$ is $\mathrm{x}$-direction velocity, $\mathrm{v}$ is $\mathrm{y}$-direction velocity and $\mathrm{w}$ is $\mathrm{z}$-direction velocity. $\mathrm{K}$ $\varepsilon$ two equation model involves [50] turbulent kinetic equation (7) and dissipation rate equation (8); 


$$
\begin{gathered}
\rho \frac{d k}{d t}=\frac{\partial}{\partial x_{j}}\left[\left(\mu+\frac{\mu_{t}}{\sigma_{k}}\right) \frac{\partial k}{\partial x_{j}}\right]+P_{k}-\rho \varepsilon \\
\rho \frac{d \varepsilon}{d t}=\frac{\partial}{\partial x_{j}}\left[\left(\mu+\frac{\mu_{t}}{\sigma_{\varepsilon}}\right) \frac{\partial \varepsilon}{\partial x_{j}}\right]+c_{\varepsilon 1} P_{k} \frac{\varepsilon}{k}-c_{\varepsilon 2} \rho \frac{\varepsilon^{2}}{k}
\end{gathered}
$$

where $\mu$ is viscosity of fluid, $\mu \mathrm{t}$ is turbulent viscosity. Pk is production of turbulence and defined [50] as;

$$
P_{k}=\tau_{i j}\left(\frac{\partial u_{i}}{\partial x_{j}}\right)
$$

where $\tau_{\mathrm{ij}}$ is viscous stresses and turbulent viscosity is related [50] to $\mathrm{k}$ and $\varepsilon$ by;

$$
\mu_{t}=\rho c_{\mu} \frac{k^{2}}{\varepsilon}
$$

$\sigma_{\mathrm{k}}, \sigma_{\varepsilon}, \mathrm{c}_{\varepsilon 1}, \mathrm{c}_{\varepsilon 2}$ and $\mathrm{c}_{\mu}$ are constants and they are equal to defaults values; $1.00,1.30,1.44,1.92$ and 0.09 respectively. Detail information about k-epsilon two equations turbulence model can be achieved from most of CFD textbooks.

\section{SOLUTION METHODOLOGY AND NUMERICAL MODELLING}

The accuracy of investigation depends on the representation of numerical model and appropriate solution procedure. The selected method, CFD needs grid construction in the problem domain and it is required to create a suitable grid model for the accuracy. The density of grid elements is initially studied in some literature studies, which indicate that mesh refinement is not effective, if enough number of elements is used in the numerical model [24] and also difference between coarse and fine mesh results is small, which are compared with an experimental study [10]. The effect of used number of grid elements is searched, which illustrates that the analyzed results are similar even if the used number of elements are changed [20].

CFD investigation of vortex breakdown around a delta wing is [50] achieved a well conformity with compared experimental results.

Water channel geometry is created for providing flow environment in the analyses. Numerical model of wing and channel geometry is constructed with considering the optimum number of grid elements. Less number of grid elements may not provide the sensitivity of observation of flow characteristics around the wing. However, the usage of great number of elements causes high computational memory and increases solution times. Optimum number of elements is constructed in the channel and they are increased around the wing for observing flow characteristics. In geometry modelling, SOLIDWORKS modelling software is used. They are imported in ANSYS ICEM CFD numerical modelling software for grid construction. Application of boundary conditions and solutions are applied in ANSYS FLUENT package software. Also, investigation of vortex formations with particle injections is applied and observed in ANSYS FLUENT package software. Results of streamline topology and 3D iso-values of different flow properties are illustrated with TECPLOT post-processor software.

\section{NUMERICAL MODELS OF THE CHANNEL AND WING}

In Figure 1, numerical model of water channel geometry is illustrated, has a dimension of a width of 927 $\mathrm{mm}$, a depth of $610 \mathrm{~mm}$ and a length of $4928 \mathrm{~mm}$. One of the tip areas is determined as fluid inlet and the other side is determined as fluid outlet. Other areas are determined as wall, which do not allow to fluid pass. Wing is placed at the center of channel and fixed with respect to the used angle of attack.

Inlet turbulent intensity is approximately selected as $0.3 \%$, which is commonly used in experimental studies [43-44,46]. Water properties are used at normal room conditions in the numerical analyses, have a density of 1.000 
$\mathrm{kg} / \mathrm{m} 3$ and a viscosity of $0.001003 \mathrm{~kg} / \mathrm{ms}$. Particle injection is used in some cases for observing vortices around the wing in the flow. Particles have no masses and move directly with free-stream flow. They are injected at a certain distance from front of the wing. Approximately 20-30 arms of particles are spread from injection location. No gravity effect is added in the analyses.

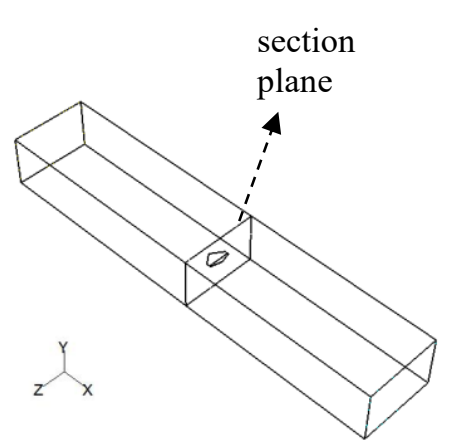

(a)

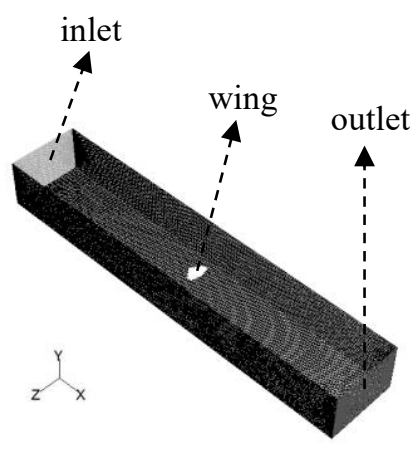

(b)

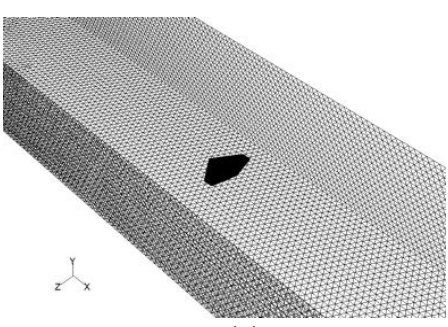

(c)

Figure 1. Numerical model of channel and wing, a) channel, wing location and section plane, b) numerical model of channel and wing, c) magnify view of channel inside and wing.

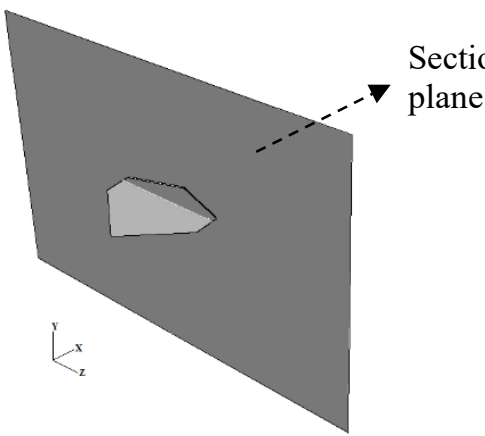

(a)

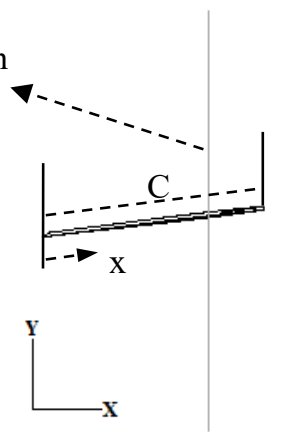

(b)

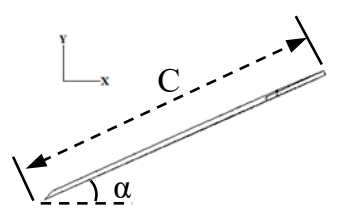

(c)

Figure 2. Section plane location on wing, a) isometric view, b) side view; c) illustration of angle of attack ( $\alpha$ )

Streamline topology is illustrated on a created section plane inside of the channel, which gives some information about vortex structures around the wing. Isometric and side view of section plane are shown in Figure 2 and it is placed at $\mathrm{x} / \mathrm{C}=0.7$, where $\mathrm{x} / \mathrm{C}$ is the ratio of plane distance from tip of wing to length of wing. The angle of attack $(\alpha)$ is also illustrated in Figure 2.

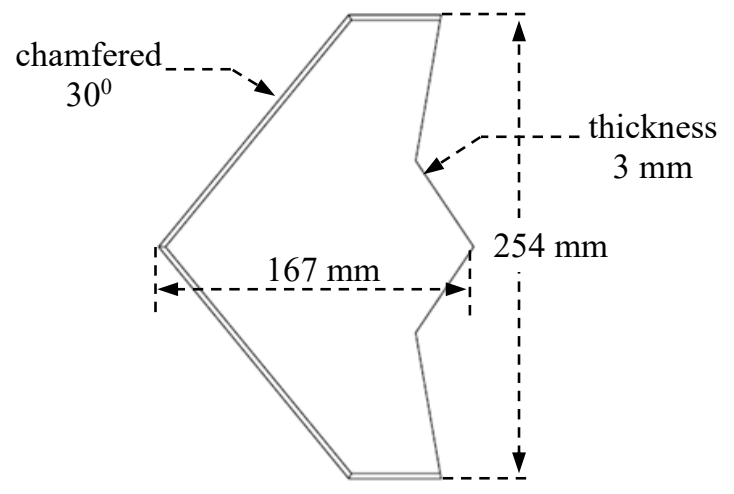

Figure 3. Lambda wing type of unmanned combat air vehicle 
The used angles of attacks are $7^{\circ}, 13^{\circ}, 17^{\circ}, 25^{\circ}, 30^{\circ}, 35^{\circ}, 40^{\circ}$ and $45^{\circ}$. Lambda wing model is given in Figure 3. The wing has a width of $254 \mathrm{~mm}$, a chord length (C) of $167 \mathrm{~mm}$ and a thickness of $3 \mathrm{~mm}$. Its leading edges are chamfered with an angle of $30^{\circ}$ and edges are not rounded. Free-stream flow velocity is determined as $60.1 \mathrm{~mm} / \mathrm{s}$ based on a constant Reynolds number of 10000 and chord length of lambda wing with respect to the study [43-44]. The total length of the flow domain is as 29.5 chord length, C. Grid structure of lambda wing model is given in Figure 4. The whole numerical model consists of approximately 3.000.000 grid elements, which includes mapped meshing technique that is used for setting number of elements efficiently.
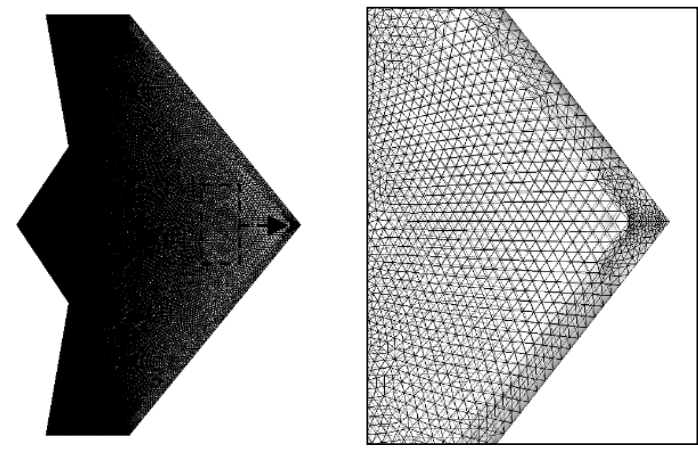

Figure 4. Numerical model of lambda wing geometry and closer view of tip locations

\section{NUMERICAL MODELS OF THE CHANNEL AND WING}

The essence of flow is unsteady/time dependent behavior, which causes to complicate the analysis of flow characteristics. A similar case study in literature shows that both steady and averaged unsteady results give [49] the same results with respect to compared experimental studies [43-44,46]. Formation of vortex location and rotation in both steady and unsteady results have similar characteristics. Consequently, steady flow analysis is used for saving CPU time in all cases in this study. Particle injection, streamline topology, velocity contours and iso-value results are given in this section. Results of streamline topology are illustrated for side half section of wing. Case solutions were applied by using CFD [49-50] and compared experimental studies [43-44], which had the same geometries and conditions. Compatible results were obtained, and results can be accessed from stated studies [49-50].

\section{DETECTION OF VORTEX FORMATIONS WITH PARTICLE INJECTIONS AROUND LAMBDA WING}

Observation of flow characteristics of the wing is usually obtained by dye injections in water channel or smoke flow in tunnel tests. These applications have some advantages and disadvantages. Particle injections are used in CFD analyses for observing the similar responses. Different kinds of particles and their injection properties are available. In this analysis, the particles are injected from front of the wing and have no mass. Some particles are widely spread from injection location and do not interact with vortices around wing. They move freely with free stream. Some injected particles interact with vortices around the wing and provide to observation of vortices and formation of vortex breakdown easily.

In Figure 5, particle injection results are given from top view of the wing for low and moderate angles of attack. Initial flow distortions are detected at $\mathrm{x} / \mathrm{C}=0.5$. Two vortex arms are observed, and they spread on wing surface when they move with free stream. Particles are not widely spread at the end of wing. But they extend to sides of wing when angle of attack is increased to $13^{\circ}$. At the same $\mathrm{x} / \mathrm{C}=0.5$ location, particle distortions are detected, but changes of particle direction get larger. Small swirls occur at the end of wing. When the primary vortex [52] occurs, a more complex vortex system develops above the delta wing and similar phenomena begin at this angle in this analysis. Two vortex arms are easily seen by means of high twisting of injected particles in the results of angle of attack of $17^{0}$. Decomposition location of particles is detected at $\mathrm{x} / \mathrm{C}=0.3$ and further sections of particles are evidently twisted. Small swirls at the end of wing get dense and more interact with effect of wing end. Swirling of injected particles nearly begins at the front edge of wing when angle of attack is equal to $25^{\circ}$. Movement of particles to side of wing occurs rapidly at $\mathrm{x} / \mathrm{C}=0.3$ in right and $\mathrm{x} / \mathrm{C}=0.4$ in left vortex arms. Also, high swirling effect is dominant in the two vortex arms. Density of small swirls at the end of wing begins to vanish. An expansion location 
of swirling particles is detected at $\mathrm{x} / \mathrm{C}=0.4$ in the left of vortex arm, where indicates location of vortex breakdown. In a surface flow visualization study of delta wing in literature, vortex breakdown is [53] detected at the angle of attack of $15^{0}$ at the trailing edge and at angle of attack of $20^{\circ}$ at the leeward side over the wing. The results thus indicate that the formation of vortices is smoother around lambda wing rather than compared similar delta wings.
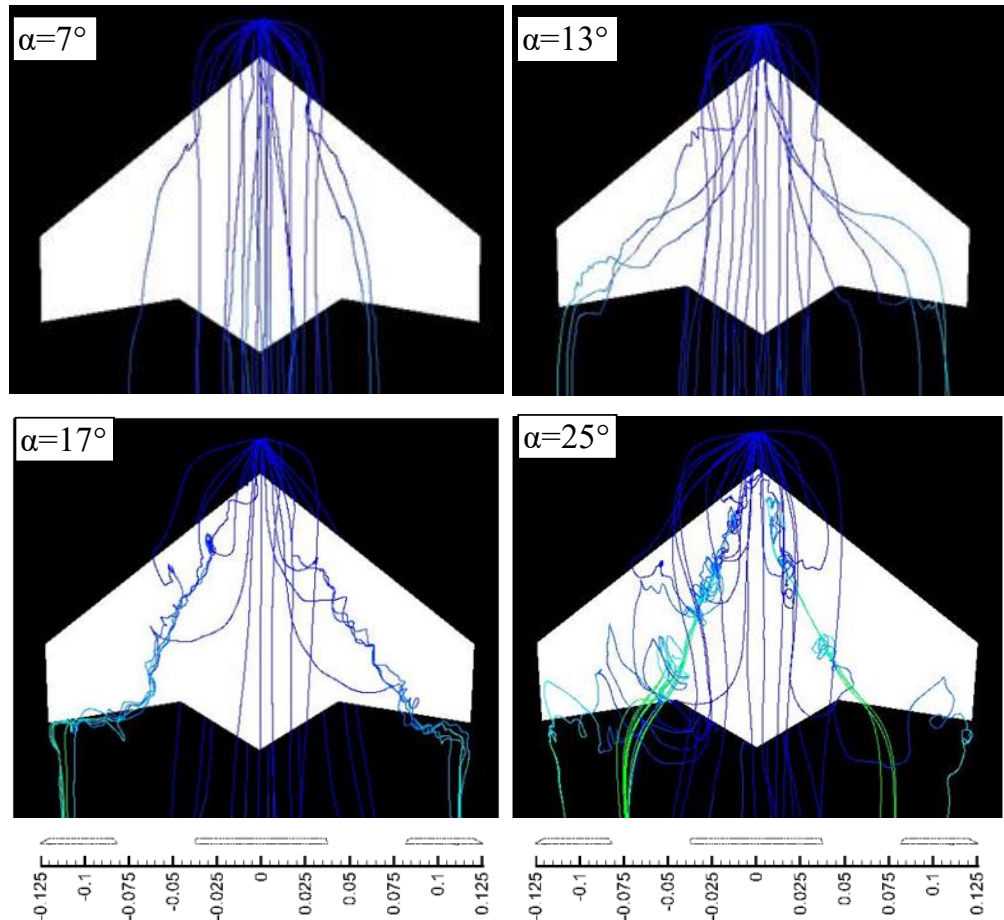

Figure 5. Particle injections results of lambda wing at low and moderate angles of attack $\left(7^{\circ}, 13^{\circ}, 17^{\circ}, 25^{\circ}\right)$
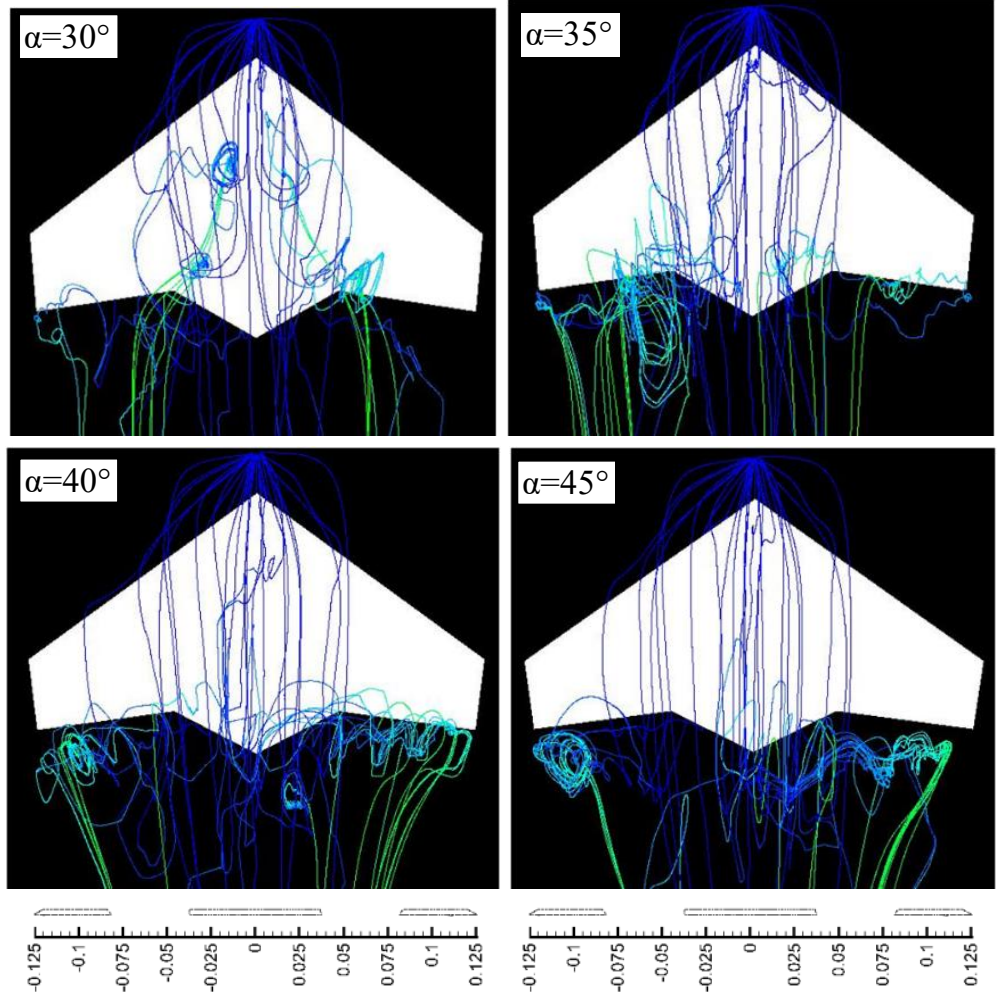

Figure 6. Particle injections results of lambda wing at high angles of attack $\left(30^{\circ}, 35^{\circ}, 40^{\circ}, 45^{\circ}\right)$. 
In Figure 6, particle injections results are given for high angles of attack. In results of angle of attack of $30^{\circ}$, deposition of particles occurs at $\mathrm{x} / \mathrm{C}=0.3$ and expands at $\mathrm{x} / \mathrm{C}=0.32$ where vortex breakdown is detected. In further sections, vortices get widespread and increase at the end of wing, especially at $\mathrm{x} / \mathrm{C}=0.9$. Great vortices coil around vortex arms. In results of angle of attack of $35^{\circ}$, direction of particles changes rapidly, and particles spread to sides at the end of wing. Deposition of vortices occurs at the backside of wing and includes high swirls. Vortices at the sides flow inward direction to behind of wing. Most of vortices occur at the backside of wing and vortex accumulation occurs the size of a wing. Similar vortex behavior is detected in the results of $45^{\circ}$. However, vortex formations move away from backside of wing. Vortex density at the sides increases.
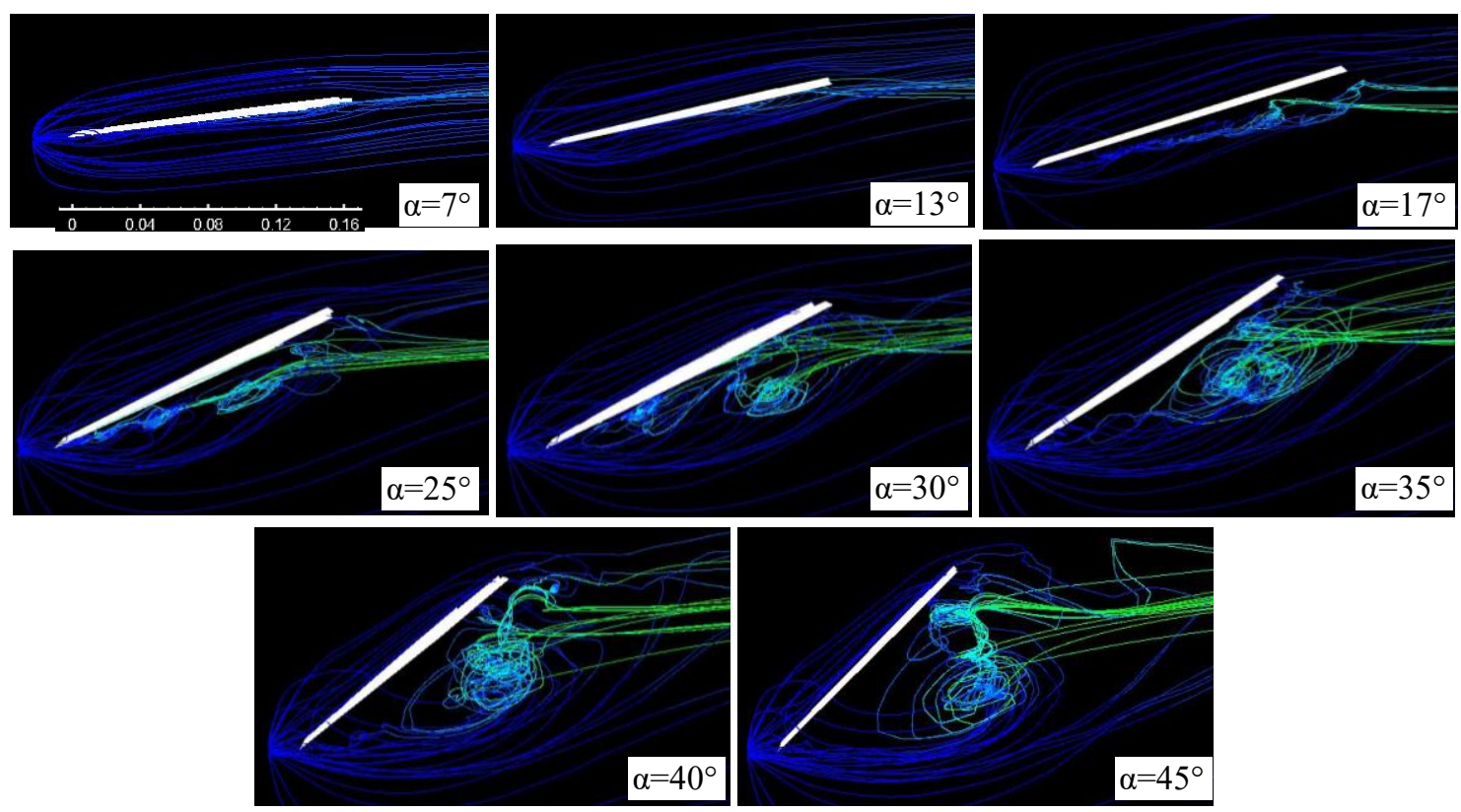

Figure 7. Side view of particle injections results of lambda wing at low, moderate and high angles of attack (from $7^{\circ}$ to $45^{\circ}$ ).

Side view of particle injections is shown in Figure 7. Disturbances are observed at the below of wing in the results of angle of attack of $7^{\circ}$, which are small sizes. Most of injected particles move with free stream smoothly. When angle of attack is increased to $13^{\circ}$, swirls is detected in particles. Swirls are concentrated at $\mathrm{x} / \mathrm{C}=0.8$ and at the end of wing. Vortex cores are observed in the results of angle of attack of $17^{\circ}$. Swirling of particles begins at $\mathrm{x} / \mathrm{C}=0.2$ and formation of dense vortices occurs at $\mathrm{x} / \mathrm{C}=0.75$ and $\mathrm{x} / \mathrm{C}=0.95$. At these vortex formation locations, particles try to move opposite direction of free stream flow. Expansion of particles is detected at $\mathrm{x} / \mathrm{C}=0.72$. Vortex formations begin nearly at front edge of wing in the results of angle of attack of $25^{\circ}$. Three dense vortex locations are detected at $\mathrm{x} / \mathrm{C}=0.15,0.3$ and 0.7 . Initial formation of a spiral type of vortex breakdown is observed at $\mathrm{x} / \mathrm{C}=0.32$. Large particle expansions are detected at the later stages of $\mathrm{x} / \mathrm{C}=0.7$. Vortex core at $\mathrm{x} / \mathrm{C}=0.7$ increases with respect to increased angle of attack to $30^{\circ}$. Expansion of injected particles is detected at $x / C=0.29$. This location indicates vortex breakdown. Particles get spiral structure at the tip of wing. Tip edge vortices move away from below surface of wing and they accumulate with great swirls at the further sections of $\mathrm{x} / \mathrm{C}=0.5$. Swirls approach to end of wing and then move with free stream. Vortex core increases when angle of attack is equal to $40^{\circ}$. Tip edge vortices nearly move with free stream at the below of wing and join with great vortices. In further increment of angle of attack to $45^{\circ}$, the size of vortex structure below the wing increases more. Nearly the size of swirls reaches chord length of wing. 


\section{STRUCTURE OF STREAMLINE TOPOLOGY OF LAMBDA WING ON SECTION PLANE}

Streamlines can be used for observing vortex formations and swirls around the wing which are constructed from velocity vectors. A section plane is created, where is at $\mathrm{x} / \mathrm{C}=0.7$ for gathering more detail information. Half of the wing results are given in streamline topology. Streamline topologies are given in Figure 8 and 9. Low and medium angles of attack results are given in Figure 8.
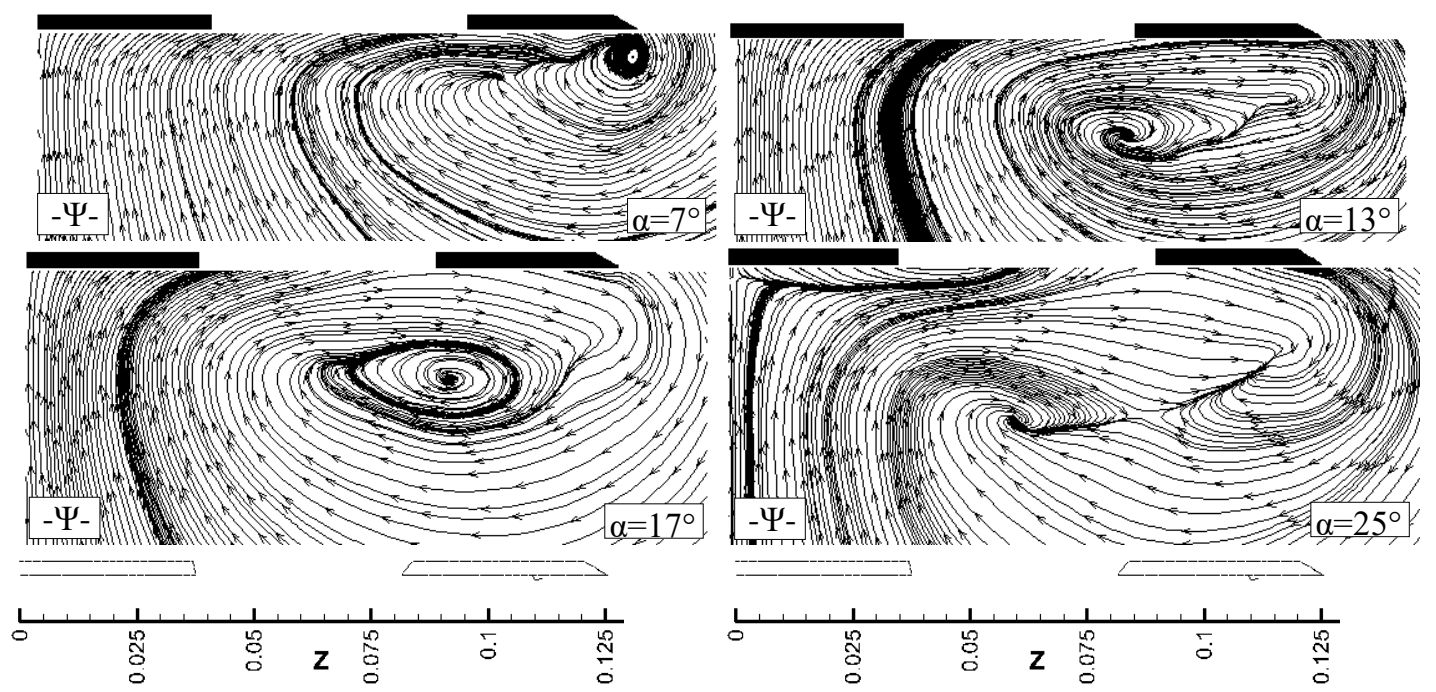

Figure 8. Streamline topology results of lambda wing at $\mathrm{x} / \mathrm{C}=0.7$ when angle of attack changes from $7^{\circ}$ to $25^{\circ}$.
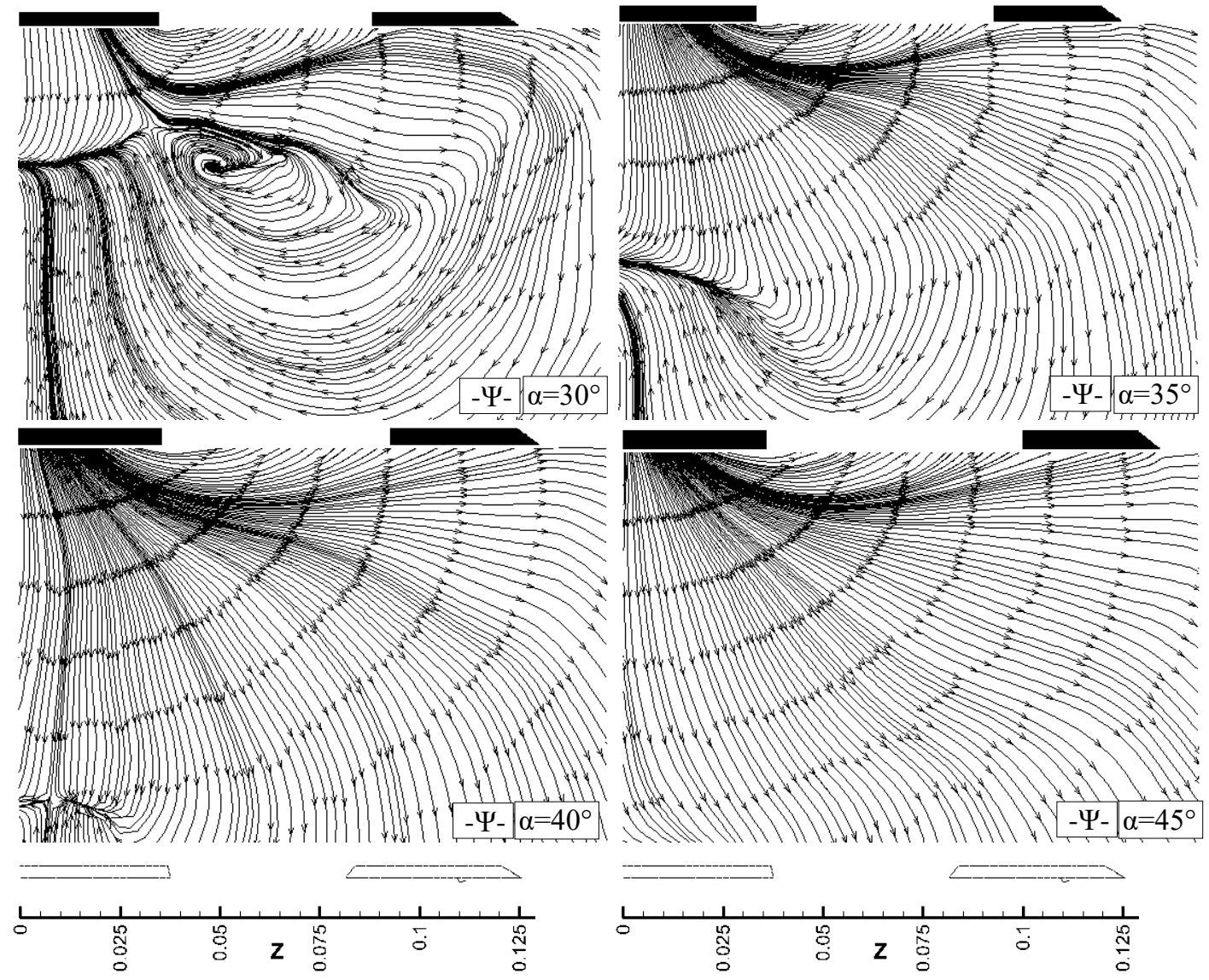

Figure 9. Patterns of streamline topology of numerical results for lambda wing at $\mathrm{x} / \mathrm{C}=0.7$ when the angle of attack changes from $30^{\circ}$ to $45^{\circ}$. 
A vortex pattern occurs below the edge of wing at angle of attack of $7^{\circ}$. When increasing angle of attack to $13^{\circ}$, vortex core begins to move center of wing with rotating. Vortex core occurs from streamlines which rotates clockwise direction. Location of vortex core nearly does not change when angle of attack is equal to $17^{\circ}$. However, formation of vortex core is more visible, and a free shear layer is observed around the core. The core separates into two parts in the results of angle of attack of $25^{\circ}$. The first one moves the center of wing and the second goes to edge of wing. A layer formation is observed between these cores.

The second vortex core disappears, and the first core continues to move center of wing with rotating in Figure 9. Characteristics of streamlines near the center of wing change and they shift their direction from right to left in the results of $30^{\circ}$. Vortex core disappears in the results of $35^{\circ}$. The layer near the center of wing moves to downstream. In the results of $45^{\circ}$, nearly no vortex core is observed. Free shear layer begins to disappear and streamlines freely spread. No vortex structures are detected at this section plane location in the results of angle of attack of $45^{\circ}$. In literature, at high angles of attack before the stall, the shear layer reattachment becomes [54] an important source of buffeting. This phenomenon is not observed at $\mathrm{x} / \mathrm{C}=0.7$ location.

\section{VELOCITY CONTOURS OF TOPOLOGY ALONG THE CENTER AND AROUND LAMBDA WING}

The sudden expansion of vortices gives a sign for vortex breakdown. Various kinds of studies are available in literature for observation of effects of vortices and their determination. A relationship is detected between the core stagnation pressure difference with outer flow and the size of vortex core [55]. Hence it is suitable to check velocity and pressure difference between formed layers around the wing.

Results of velocity contours around lambda wing are given in Figure 10 on a section plane which passes from centroid of the wing. Stagnation points (sp) are illustrated in all results. There is only one stagnation point occurs at the first angle of attack, where occurs in front of the wing. In further increments of angle of attack, two stagnation points occur. One of the stagnation points is detected in front of the wing in all results. However, the other stagnation point occurs upper surface of the wing and its location changes with respect to angle of attack. It is detected at $\mathrm{x} / \mathrm{C}=0.35,0.47,0.5,0.61,0.68,0.70$ and 0.76 when angle of attack is equal to $13^{\circ}, 17^{\circ}, 25^{\circ}, 30^{\circ}, 35^{\circ}, 40^{\circ}$ and $45^{\circ}$, respectively.

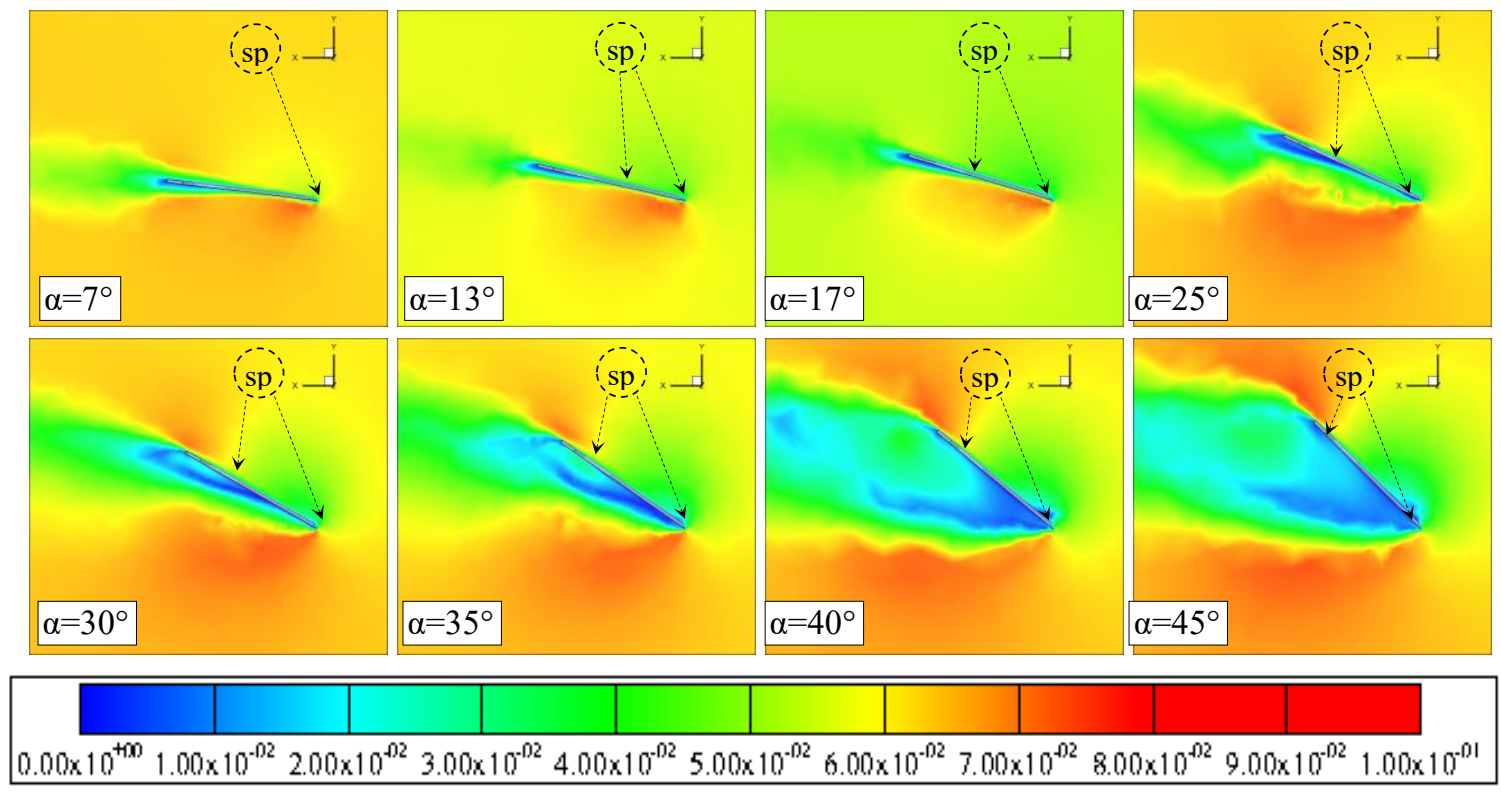

Figure 10. Velocity contours of lambda wing with various angles of attack. 
High velocity profile is observed at the below surface of wing and it leans to direction of chord length. Similar high velocity profile is observed in the results of $13^{\circ}$ and $17^{\circ}$. An expansion of low velocity profile is detected at $\mathrm{x} / \mathrm{C}=0.79$ in the results of $17^{\circ}$. However, in the results of $25^{\circ}$, high velocity profile rapidly increases and spread below direction of wing. A medium velocity profile occurs between high velocity profile and below surface of wing. A dense fluctuation occurs at medium and high velocity profile. Continuity of fluctuation vanishes in some locations, between $\mathrm{x} / \mathrm{C}=0.25$ and 0.5 . Formation of vortex breakdown is detected at $\mathrm{x} / \mathrm{C}=0.35$. Low velocity profile at the end of wing expands. Separation zones of velocity vectors in a literature study point [9] that a very strong reversed flow region can be found, which may be also cause to re-attachment of the mean flow in further section of the wing surface. Low velocity profile begins to separate from below surface at the end of wing in the results of $30^{\circ}$. High velocity profile density decreases and recedes from wing. The expansion is observed at $\mathrm{x} / \mathrm{C}=0.3$. In further high angles of attack, low velocity profile spreads to below surface of wing. High velocity profile does not vanish. A high velocity profile also occurs at the upper surface of wing end. A medium velocity location occurs and expands backside of wing in the results of $40^{\circ}$ and $45^{\circ}$. The region of separated flow [7] enlarges by increasing the angle of attack, which is also valid in this result.

\section{D MAPPING OF VORTICITY FIELD}

Vortex breakdown depends on the structure of vortices. The changes in velocity and vorticity profile increase or decrease vortices around wings. Vortices occur in $3 \mathrm{D}$, which are at $\mathrm{x}, \mathrm{y}$ and $\mathrm{z}$ directions. Vortices of $\mathrm{z}$ direction are considered in this analysis, which demonstrate effect of angle of attack clearly. One of the iso-values of $z$-vorticity is used. Only z-vorticity value of 2 is selected in demonstration of vortices.

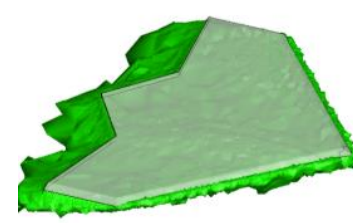

$\alpha=7^{\circ}$

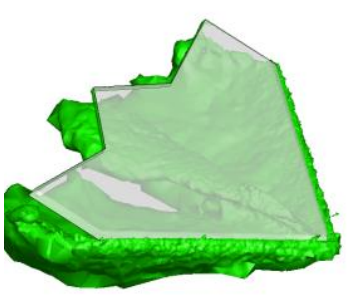

$\alpha=30^{\circ}$
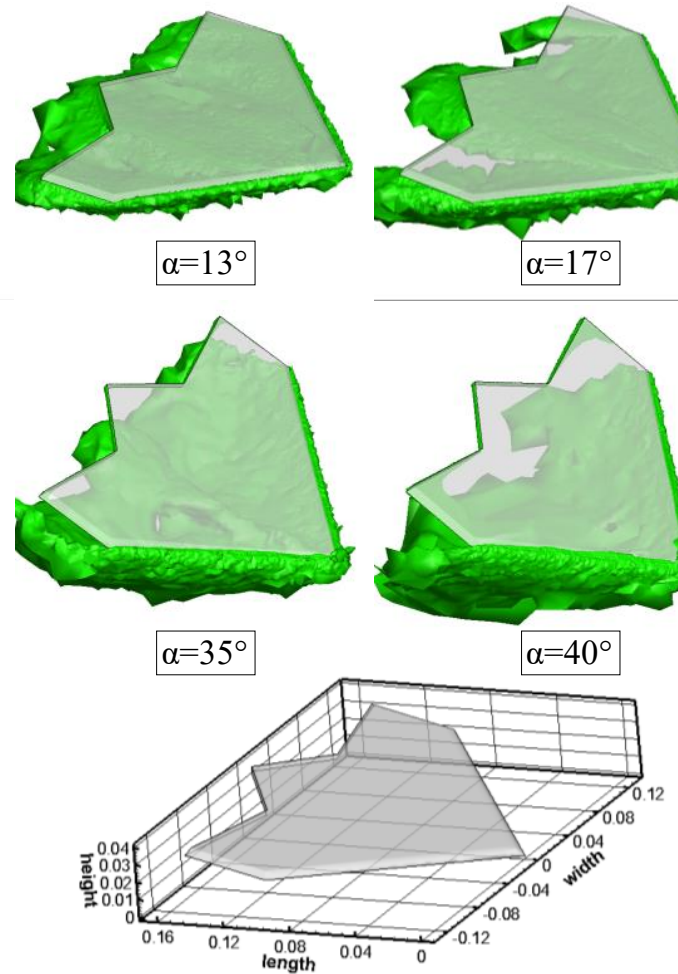
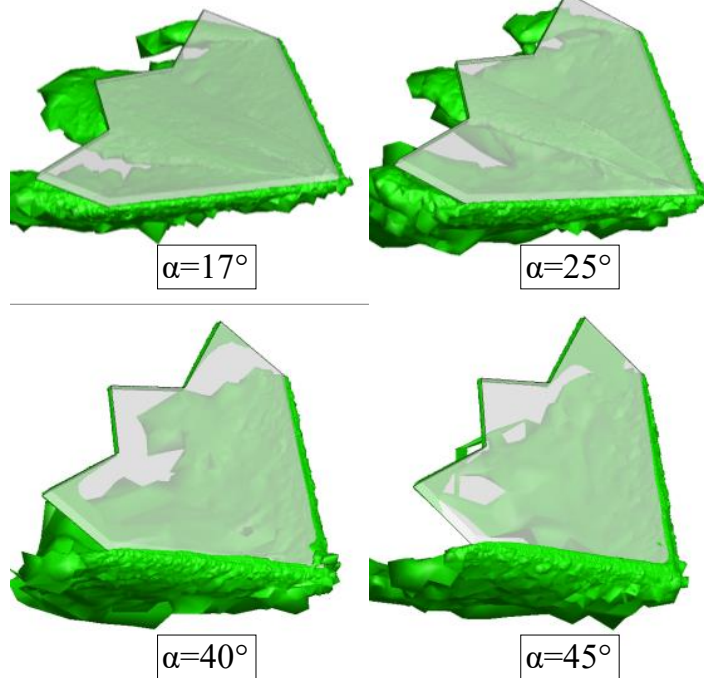

Figure 11. Illustration of z-vorticity value of 2 around the wing.

Iso-value 2 of z-vorticity is given in Figure 11. Vortices occur around below surface of wing and its backside in the results of $7^{\circ}$. When increasing angle of attack up to $25^{\circ}$, vortices become to decrease below surface of wing and form three vortex arms. The centre arm gets decreasing in the results of angle of attack of $30^{\circ}$, but it does 
not vanish. A review study [56] from literature summarizes that the axial vorticity is reduced substantially, and a large negative azimuthal vorticity is present after breakdown.

Vortices occur as a cavity at the below of wing, which fully represent the similar structure. When increasing angle of attack to $35^{\circ}$, centre of vortex arms moves down, and they become to unite other vortices. In the results of angles of attack of $40^{\circ}$ and $45^{\circ}$, only vortices at sides of wing occur. Small scale vortices occur at the end edges of wing.

\section{EFFECT OF FILLET ON VORTICITY VALUES AROUND THE WING}

The wing geometry is the most considered criteria for flow behavior around the wings. Initial design of wings includes inefficient aerodynamic geometries and needs developments. Formation of vortices can directly be reduced with suitable modifications on pre-designed wings. Changing wing aspect ratio [57], adding elliptical mounds [58] or adding small circular channels on wing surfaces [59] can control formation of vortices in a limited range. However, main effect of angle of attack on formation of vortices and vortex breakdown cannot be eliminated. Hence, new design concepts must be tried for preventing or delaying the vortex breakdown. At least, its effect must be minimized for aerodynamic performance. The analyzed lambda wing geometry has sharp corners and it is generally known that sharp corners increase effect of mechanical stresses and flow separations. Sharp corners are generally rounded which support more uniform flow around wings. Rounding the leading edges of a delta wing [60] provides to delay flow separation. The rounding effect of leading edges can also be seen in the studies of Schütte and Lüdeke [16], Cummings and Schütte [25] and Fritz [27].

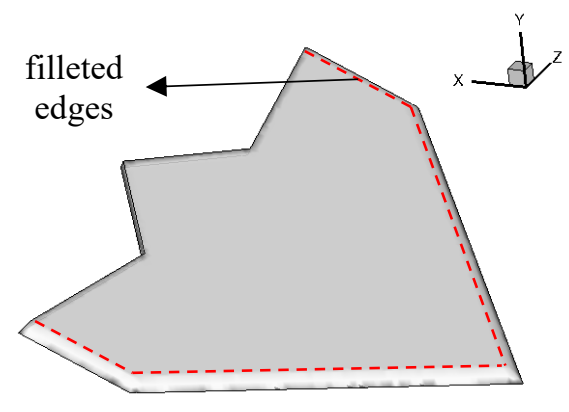

Figure 12. Filleted edges of the wing

Table 1. Effect of fillet on vorticity values around lambda wing (min, max values)

\begin{tabular}{|c|c|c|c|}
\hline fillet radius & -z vorticity & + z vorticity & vorticity mag \\
\hline \hline no fillet & -125.57 & 168.69 & 181.68 \\
\hline $3 \mathrm{~mm}$ & -54.84 & 50.51 & 55.41 \\
\hline $6 \mathrm{~mm}$ & -57.69 & 45.38 & 59.02 \\
\hline $9 \mathrm{~mm}$ & -60.26 & 47.2 & 64.22 \\
\hline
\end{tabular}

The effect of fillet on magnitude of vortices around wing is investigated. Rounded edges are marked as red lines and they are shown in Figure 12. Rounding/fillet radius and magnitudes of vortices are given in table 1. It is detected that most of the vortex magnitudes occur in front of the wing and its edge locations. z-direction vortices have a dominant role on total vortices. Vortices are rapidly decreased with respect to addition of rounding at edges. Rounding of marked edges with a radius of $3 \mathrm{~mm}$ directly decreases values of vortices of total and $\mathrm{z}$ directions. Rounding radius of $6 \mathrm{~mm}$ and $9 \mathrm{~mm}$ results have also less vortex values than sharp edge results.

\section{CONCLUSION}

In this study, flow characteristics around a lambda wing are observed and vortex breakdown is investigated under various angles of attack, especially up to $45^{\circ}$. CFD is used for investigation of flow behavior. Water properties 
are used as fluid properties and Reynolds number is selected as 10000 . Some findings in the study can be summarized as;

Disruptions in the flow begin at the first angle of attack $\left(7^{\circ}\right)$ and in general, two separated vortex arms occur. These arms go close to the wing sides. Vortex structures are easily observed at the angle of attack of $13^{\circ}$. Vortex breakdown is initially detected in the results of $17^{\circ}$ and its location is approximately at $\mathrm{x} / \mathrm{C}=0.72$. Critical angle of attack is determined as $25^{\circ}$, which causes to vortex breakdown around the wing at $\mathrm{x} / \mathrm{C}=0.32$. In the result of $30^{\circ}$, vortex breakdown is detected at $\mathrm{x} / \mathrm{C}=0.29$. Vortex structures and its core move away from the surface of wing. A great whirl occurs at the highest angle of attack, which is approximately equal to chord length of the wing. In the particle injection results, particle depositions are detected at the determined locations around the wing and they disrupt flow characteristics.

Streamline topology results indicate that a vortex core occurs at the below surface of wing edge. It moves with rotating to center of wing by increasing angle of attack $\left(13^{\circ}\right)$. A vortex core with smooth bands is observed at the results of $17^{\circ}$. The core separates into two parts when angle of attack is equal to $25^{\circ}$ and in further increments of angle of attack, the separated core gets vanish. The other continues to move center of the wing. At high angles of attack $\left(>30^{\circ}\right)$, streamlines get widen to downstream and free-shear layers vanish.

In the first angle of attack $\left(7^{\circ}\right)$, only one stagnation point is detected on the wing. In further increments of angle of attack, two stagnation points are observed. One of them occurs at the front of the wing in all results. The other occurs on the upper surface of the wing and moves to back side of the wing with increasing angle of attack. Velocity contours indicate that high velocity profile expands and fluctuates with increased angle of attack. Low velocity profile begins to cover the backside location of wing. Location of vortices begins to move away from below surface of wing with increased angle of attack in the iso-values of z-vorticity of 2. A geometrical change is applied by using rounding of the upper leading edges of wing. Vortex values decrease with addition of a rounding of $3 \mathrm{~mm}$ radius. In all observations and findings, angle of attack can be increased up to $30^{\circ}$ and it is hard to provide fly conditions in further increments of angle of attack. In line of this work, new techniques will be investigated for preventing and delaying the vortex formations and breakdown, especially at high angles of attack.

\section{NOMENCLATURE}

$\begin{array}{ll}\mathrm{R}_{\mathrm{e}} & \text { Reynolds number } \\ \mathrm{U}_{\infty} & \text { free-stream velocity }[\mathrm{mm} / \mathrm{s}] \\ \Psi & \text { stream function } \\ \rho & \text { fluid density }\left[\mathrm{kg} / \mathrm{m}^{3}\right] \\ \mathrm{u},, \mathrm{v}, \mathrm{w}^{2}, & \text { velocity fluctuations } \\ \mathrm{C} & \text { chord length of the wing }[\mathrm{mm}] \\ -\Psi- & \text { steady streamline } \\ \mathrm{x} & \text { results taken location along the chord of the wing }[\mathrm{mm}] \\ \alpha & \text { angle of attack [0] } \\ \mathrm{k} & \text { turbulent kinetic energy } \\ \varepsilon & \text { turbulent dissipation rate } \\ \mathrm{u} & \text { X-direction velocity }[\mathrm{mm} / \mathrm{s}] \\ \mathrm{v} & \text { y-direction velocity }[\mathrm{mm} / \mathrm{s}] \\ \mathrm{W} & \text { z-direction velocity }[\mathrm{mm} / \mathrm{s}] \\ \mathrm{P}_{\mathrm{k}} & \text { production of turbulent kinetic energy }(\mathrm{TKE}) \\ \mu & \text { molecular viscosity }[\mathrm{kg} / \mathrm{ms}] \\ \mu_{\mathrm{t}} & \text { turbulent viscosity } \\ \sigma_{\mathrm{k}}, \sigma_{\varepsilon}, \sigma_{\varepsilon 1}, \sigma_{\varepsilon 2}, \sigma_{\mu} & \text { k-epsilon turbulence model constants }\end{array}$




\section{REFERENCES}

[1] Narayan KY, Seshadri SN. Types of flow on the lee side of delta wings. Prog. Aerospace Sci. 1997;33:167257.

[2] Lu Z, Zhu L. Study on forms of vortex breakdown over delta wing. Chinese Journal of Aeronautics 2004;17(1):13-16.

[3] Jacquin L. On trailing vortices: a short review. International Journal of Heat and Fluid Flow 2005;26:843854.

[4] Lucca-negro O, Doherty T. Vortex breakdown - a review. Progress in Energy and Combustion Science 2001;27:431-481.

[5] Jacquin L, Fabre D, Sipp D, Coustols E. Unsteadiness, instability and turbulence in trailing vortices. C. R. Physique 2005;6:399-414.

[6] Sheta EF, Huttsell LJ. Characteristics of f/a-18 vertical tail buffeting. Journal of Fluids and Structures 2003;17:461-477.

[7] Yayla S, Canpolat C, Sahin B, Akilli H. The effect of angle of attack on the flow structure over the nonslender lambda wing. Aerospace Science and Technology 2013;28:417-430.

[8] Cai J, Pan S, Li W, Zhang Z. Numerical and experimental investigations of a nonslender delta wing with leading-edge vortex flap. Computers \& Fluids 2014;99:1-17.

[9] Shan H, Jiang L, Liu C. Direct numerical simulation of flow separation around a naca 0012 airfoil. Computers \& Fluids 2005;34:1096-1114.

[10] Dang H, Yang Z. Vortex breakdown over delta wing and its induced turbulent flow. 2nd International Conference on Computer Engineering and Technology 2010;5:473-477.

[11] Gursul I, Allan MR, Badcock KJ. Opportunities for the integrated use of measurements and computations for the understanding of delta wing aerodynamics. Aerospace Science and Technology 2005;9:181-189.

[12] Kyriakou M, Missirlis D, Yakinthos K. Numerical modeling of the vortex breakdown phenomenon on a delta wing with trailing-edge jet-flap. International Journal of Heat and Fluid Flow 2010;31:1087-1095.

[13] Breitsamter C. Unsteady flow phenomena associated with leading-edge vortices. Progress in Aerospace Sciences 2008;44:48-65.

[14] Boelens OJ. CFD analysis of the flow around the X-31 aircraft at high angle of attack. Aerospace Science and Technology 2012;20:38-51.

[15] Munro CD, Krus P, Jouannet C. Implications of scale effect for the prediction of high angle of attack aerodynamics. Progress in Aerospace Sciences 2005;41:301-322.

[16] Schütte A, Lüdeke H. Numerical investigations on the VFE-2 65-degree rounded leading edge delta wing using the unstructured DLR TAU-code. Aerospace Science and Technology 2013;24:56-65.

[17] Gordnier RE, Visbal MR. Computation of the aeroelastic response of a flexible delta wing at high angles of attack. Journal of Fluids and Structures 2004;19:785-800.

[18] Vlahostergios Z, Missirlis D, Yakinthos K, Goulas A. Computational modeling of vortex breakdown control on a delta wing. International Journal of Heat and Fluid Flow 2013;39:64-77.

[19] Attar PJ, Gordnier RE. Aeroelastic prediction of the limit cycle oscillations of a cropped delta wing. Journal of Fluids and Structures 2006;22:45-58.

[20] Gordnier RE, Visbal MR. Numerical simulation of delta-wing roll. Aerospace Science and Technology 1998;6:341-351.

[21] Miller GD, Williamson CHK. Turbulent structures in the trailing vortex wake of a delta wing. Experimental Thermal and Fluid Science 1997;14:2-8.

[22] Crivellini A, D'Alessandro V, Bassi F. High-order discontinuous Galerkin RANS solutions of the incompressible flow over a delta wing. Computers \& Fluids 2013;88:663-677.

[23] Takovitskii SA. The optimal conical twist of a delta wing. Journal of Applied Mathematics and Mechanics 2012;76:103-109.

[24] Mary I. Large eddy simulation of vortex breakdown behind a delta wing. International Journal of Heat and Fluid Flow 2003;24:596-605. 
[25] Cummings RM, Schütte A. Detached-eddy simulation of the vortical flow field about the VFE-2 delta wing. Aerospace Science and Technology 2013;24:66-76.

[26] Sun D, Li Q, Zhang H. Detached-eddy simulations on massively separated flows over a 76/400 double-delta wing. Aerospace Science and Technology 2013;30:33-45.

[27] Fritz W. Numerical simulation of the peculiar subsonic flow-field about the VFE-2 delta wing with rounded leading edge. Aerospace Science and Technology 2013;24:45-55.

[28] Levinski O. Review of vortex methods for simulation of vortex breakdown. Australia: DSTO Aeronautical and Maritime Research Laboratory, 2001.

[29] Sohn MH, Chang JW. Effect of a centerbody on the vortex flow of a double-delta wing with leading edge extension. Aerospace Science and Technology 2010;14:11-18.

[30] Lambert C, Gursul I. Characteristics of fin buffeting over delta wings. Journal of Fluids and Structures 2004;19:307-319.

[31] Tang DM, Henry JK, Dowell EH. Effects of steady angle of attack on nonlinear gust response of a delta wing model. Journal of Fluids and Structures 2001;16(8):1093-1110.

[32] Pashilkar AA. Surface pressure model for simple delta wings at high angles of attack. Sadhana 2001;26(6):495-515.

[33] Mian HH, Wang G, Ye Z. Numerical investigation of structural geometric nonlinearity effect in high-aspectratio wing using CFD/CSD coupled approach. Journal of Fluids and Structures 2014;49:186-201.

[34] Mitchell AH, Delery J. Research into vortex breakdown control. Progress in Aerospace Sciences 2001;37:385-418.

[35] Stanewsky E. Adaptive wing and flow control technology. Progress in Aerospace Sciences 2001;37:583-667.

[36] Gursul I., Wang Z, Vardaki E. Review of flow control mechanisms of leading-edge vortices. Progress in Aerospace Sciences 2007;43:246-270.

[37] Gursul I, Yang H. Vortex breakdown over a pitching delta wing. Journal of Fluids and Structures 1995;9:571 583.

[38] Özgören M, Şahin B, Rockwell D. Vortex breakdown from a pitching delta wing incident upon a plate: flow structure as the origin of buffet loading. Journal of Fluids and Structures 2002;16(3):295-316.

[39] Blackwelder RF, Liu D, Jeon W. Velocity perturbations produced by oscillating delta wing actuators in the wall region. Experimental Thermal and Fluid Science 1998;16:32-40.

[40] Crouch J. Airplane trailing vortices and their control. C. R. Physique 2005;6:487-499.

[41] Srigrarom S, Lewpiriyawong N. Controlled vortex breakdown on modified delta wings. Journal of Visualization 2007;10(3):299-307.

[42] Yilmaz TO, Rockwell D. Flow structure on a three-dimensional wing subjected to small amplitude perturbations. Exp Fluids 2009;47:579-597.

[43] Yaniktepe B. Origin and control of vortex breakdown of unmanned combat air vehicles. Ph.D. Dissertation, Mechanical Engineering Dept. Adana: Cukurova University, 2006.

[44] Yaniktepe B, Rockwell D. Flow Structure on diamond and lambda planforms trailing edge region. AIAA Journal 2005;43(7):1490-1500.

[45] Yavuz MM, Elkhoury M, Rockwell D. Near-surface topology and flow structure on a delta wing. AIAA Journal 2004;42(2):332-340.

[46] Elkhoury M. Aerodynamics of unmanned combat air vehicles: flow structure and control. Ph.D. Dissertation, Mechanical Engineering and Mechanics Dept. Pennsylvania: Lehigh University Press, 2004.

[47] Goruney T, Rockwell D. Flow past a delta wing with a sinusoidal leading edge: near-surface topology and flow structure. Exp Fluids 2009;47:321-331.

[48] Vlahostergios Z, Missirlis D, Yakinthos K, Goulas A. Computational modeling of vortex breakdown control on a delta wing. International Journal of Heat and Fluid Flow 2013;39:64-77.

[49] Yavuz MM. Numerical analysis of vortex breakdown of unmanned combat air vehicles. M.Sc. Dissertation, Mechanical Engineering Dept. Adana: Cukurova University, 2011.

[50] Yavuz MM, Pinarbasi A. Investigation of flow characteristics and vortex breakdown of a delta wing. 6th 
Ankara International Aerospace Conference, METU Press. 2011;1-11.

[51] Hoffmann KA, Chiang ST. Computational fluid mechanics volume III. 4th ed. Engineering Education System, 2000.

[52] Konrath R, Klein C, Schröder A. PSP and PIV investigations on the VFE-2 configuration in sub- and transonic flow. Aerospace Science and Technology 2013;24:22-31.

[53] Saha S, Majumdar B. Flow visualization and CFD simulation on $65^{\circ}$ delta wing at subsonic condition. Procedia Engineering 2012;38:3086-3096.

[54] Gursul I, Gordnier R, Visbal M. Unsteady aerodynamics of nonslender delta wings. Progress in Aerospace Sciences 2005;41:515-557.

[55] Darmofal DL, Khan R, Greitzer EM, Tan CS. Vortex core behaviour in confined and unconfined geometries: a quasi-one-dimensional model. J. Fluid Mech. 2001;449:61-84.

[56] Nelson RC, Pelletier A. The unsteady aerodynamics of slender wings and aircraft undergoing large amplitude maneuvers. Progress in Aerospace Sciences 2003;39:185-248.

[57] Yavuz MM. Investigation of effect of wing aspect ratio on flow characteristics around unmanned combat air vehicle of X-45a under low angles of attack. IV. National Aerospace Conference. Turkish Air Force Academy Press. 2012;1-18. (in Turkish)

[58] Yavuz MM. Investigation of effect of formed mound with different shapes and heights on formation of vortices around a delta wing. 2nd National Aeronautics Technology and Applications Conference, Ege University Press. 2013;355-365. (in Turkish)

[59] Yavuz MM. Investigation of effect of opened channels at the upper surface of unmanned combat air vehicle on control of vortices. VII. National Aircraft Aviation and Aerospace Engineering Congress. Chamber of Mechanical Engineering Press. 2013;31-36. (in Turkish)

[60] Furman A, Breitsamter C. Turbulent and unsteady flow characteristics of delta wing vortex systems. Aerospace Science and Technology 2013;24:32-44. 